\title{
An analysis of patients transported by a private helicopter emergency medical service in South Africa
}

\author{
D Muhlbauer, ${ }^{1}$ MTech Emergency Medical Care; R Naidoo, ${ }^{1}$ MSc (Cardiol), MSc (Med); \\ T C Hardcastle, ${ }^{2}$ MB ChB, MMed (Chir), FCS (SA), PhD \\ ${ }^{1}$ Department of Emergency Medical Care and Rescue, Durban University of Technology, South Africa \\ ${ }^{2}$ Department of Surgery, Inkosi Albert Luthuli Central Hospital and College of Health Sciences, Nelson R Mandela School of Medicine, \\ University of KwaZulu-Natal, South Africa
}

Corresponding author: D Muhlbauer(dagmarm@dut.ac.za)

\begin{abstract}
Background. A helicopter emergency medical service (HEMS) is a specialist flying emergency service where on-board medical personnel have both the knowledge and equipment to perform complicated medical procedures. The paucity of literature describing the types of patients flown by HEMS in South Africa (SA) and their clinical outcome poses a challenge for current aeromedical services, as there is no baseline information on which to base flight criteria, staffing and policy documents. This has the potential to hamper the advancement of HEMS in SA.

Objectives. To undertake a descriptive analysis of patients flown by the Netcare 911 HEMS over a 12-month period in Gauteng and KwaZulu-Natal (KZN) provinces, SA, and to assess patient outcomes. The clinical demographics of patients transported by the HEMS were analysed, time frames from dispatch of the helicopter to delivery of the patient to the receiving hospital determined, and patient outcomes at 24 hours and 72 hours analysed.

Methods. The study utilised a retrospective quantitative, descriptive design to analyse patients transported by a private HEMS in SA. All complete records of patients transported by the Netcare 911 HEMS between 1 January and 31 December 2011 were included.

Results. The final study population comprised 537 cases, as 10 cases had to be excluded owing to incomplete documentation. Of the 537 cases, $82(15.3 \%)$ were managed by the KZN HEMS and 455 (84.7\%) by the Gauteng HEMS. Adult males were the patients most commonly flown in both Gauteng and KZN (350/455 patients (76.9\%) in Gauteng and 48/82 (58.5\%) in KZN were males, and 364/455 patients (80.0\%) in Gauteng and 73/82 (89.0\%) in KZN were adults). Motor vehicle collisions were the most common incidents necessitating transport by HEMS in both operations ( $n=193,35.9 \%)$. At the 24-hour follow-up, 339 patients $(63.1 \%)$ were alive and stable, and at the 72 -hour followup, $404(75.3 \%)$ were alive and stable.

Conclusions. The study findings provided valuable information that may have an impact on the current staffing and authorisation criteria of SA HEMS operations.
\end{abstract}

S Afr Med J 2016;106(2):201-205. DOI:10.7196/SAMJ.2016.v106i2.9919

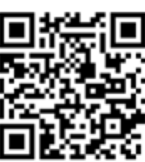

A helicopter emergency medical service (HEMS) is a specialist flying emergency service where on-board medical personnel have both the knowledge and equipment to perform complicated medical procedures. This scarce resource may be called upon in circumstances where either a traditional ground ambulance cannot reach the incident in an appropriate response time or the patient needs to be transported to an appropriate facility over a long distance or over inhospitable terrain. Air transportation has the advantages of being able to deliver a highly skilled medical team to an incident speedily, as well as transport a patient to the most appropriate hospital instead of the closest hospital..$^{[1]}$

HEMS originated in military operations and inspired the idea of dedicated civilian air ambulances. ${ }^{[2,3]}$ The use of civilian helicopters for the transport of ill or injured patients has become an important part of modern emergency care systems. ${ }^{[4]}$

Since the 1970s, there have been a number of different HEMS operations across South Africa (SA) in both the private and public sectors. The HEMS in SA currently comprises three major service providers: Netcare 911, ER24 and the Red Cross Air Mercy Service. This study examined the Netcare 911 HEMS operations, staffed by a medical doctor and an Advanced Life Support paramedic.

Medical evacuations can be broadly categorised into primary flights (removal of a patient from the initial scene of the incident) and interfacility patient transfers. Each individual flight is authorised by a medical doctor based on predetermined flight criteria (NTC911HEMS-007-HEMS Flight Crew Requirements). However, as HEMS operations represent one of the most expensive prehospital treatment modalities, it is essential that the benefits are taken into consideration when determining procedures and policies for their use ${ }^{[5]}$ and that a developing country such as SA utilises this expensive and scarce resource cautiously. The paucity of literature on this topic poses a challenge for current aeromedical services, as there is no baseline information on which to base flight criteria, staffing and policy documents.

\section{Objectives}

To undertake a descriptive analysis of the use of a private HEMS operation over a 12-month period.

\section{Methods}

Netcare 911 helicopters were based in Midrand, Gauteng Province, and Durban North, KwaZulu-Natal Province (KZN), SA. The Gauteng and KZN HEMS operations serviced primary call-outs and interfacility transfers and were configured to transport one patient at a time. The service operated 365 days a year, with the Gauteng operation available 24 hours a day and the KZN operation during daylight hours only. The crew consisted of a pilot, a medical doctor and an Advanced Life Support paramedic. Both the doctor and the paramedic needed to meet specific criteria (NTC911-HEMS007) in 
order to be part of the HEMS crew. These criteria included Health Professions Council of South Africa registration, a minimum of 2 years' post-graduation clinical experience, currency in the American Heart Association courses, annual completion of a CAT138, and a current class II flight medical certificate. ${ }^{[6]}$

Ethical approval was obtained from the Durban University of Technology Institutional Research Ethics Committee (ref. REC36/2), and permission was also obtained from the Netcare 911 Research Committee.

A retrospective quantitative, descriptive chart review design was utilised to analyse patients transported by the Netcare 911 HEMS in SA between 1 January and 31 December 2011. Cases with incomplete documentation were excluded. Data were collected from the Clinical Audit and Reporting System (CARS) database. The documentation accessed included an electronic patient care record, flight assessment form, flight follow-up sheet and flight $\log$. The relevant data were extracted from the CARS database by the researcher and entered onto an electronic data collection tool.

The data were analysed using SPSS version 21.0 (IBM, USA), with descriptive statistics. Student's $t$-test was utilised for data with a normal distribution and the $\chi^{2}$ test or Fisher's exact test for categorical variables. The $p$-value was set at $<0.05$.

\section{Results}

A total of 547 cases were serviced by the Netcare 911 HEMS operations during the 12 -month study period. Of these, 10 had to be excluded owing to missing variables in the documentation. The Gauteng HEMS operation serviced 455 cases (84.7\%) and the KZN operation 82 (15.3\%). Chi-square tests showed a statistical significance in the call volume split between the two operations $(p<0.05$ : confidence interval $99 \%)$. Both the HEMS operations were most frequently dispatched to primary transfers, which totalled $357(66.5 \%)$ of all the cases. The remaining cases were interfacility transfers $(n=180,33.5 \%)$.

SA is divided into 52 health districts. Analysis of the records showed that the two HEMS operations generally retrieved patients from within their own provinces. However, in certain instances both the helicopters retrieved patients from outside their respective provinces. The most common districts from which cases managed by the Gauteng HEMS operation originated were the City of Johannesburg metropolitan municipality ( $n=110,24.2 \%$ of total cases),
Ekurhuleni metropolitan municipality $(n=101,22.2 \%)$, and the City of Tshwane metropolitan municipality $(n=78,17.1 \%)$. The Gauteng HEMS operation also collected 2 patients $(0.4 \%)$ from the Amajuba district municipality, which falls in KZN. The KZN HEMS operation most frequently collected patients from the eThekwini metropolitan municipality ( $n=22,26.8 \%$ ), followed by the Ugu district municipality ( $n=17,20.7 \%)$ and the uMgungundlovu district municipality $(n=16,19.5 \%)$. It also crossed over into the Eastern Cape Province to collect 2 patients (2.4\%) from the Alfred Nzo district muni-

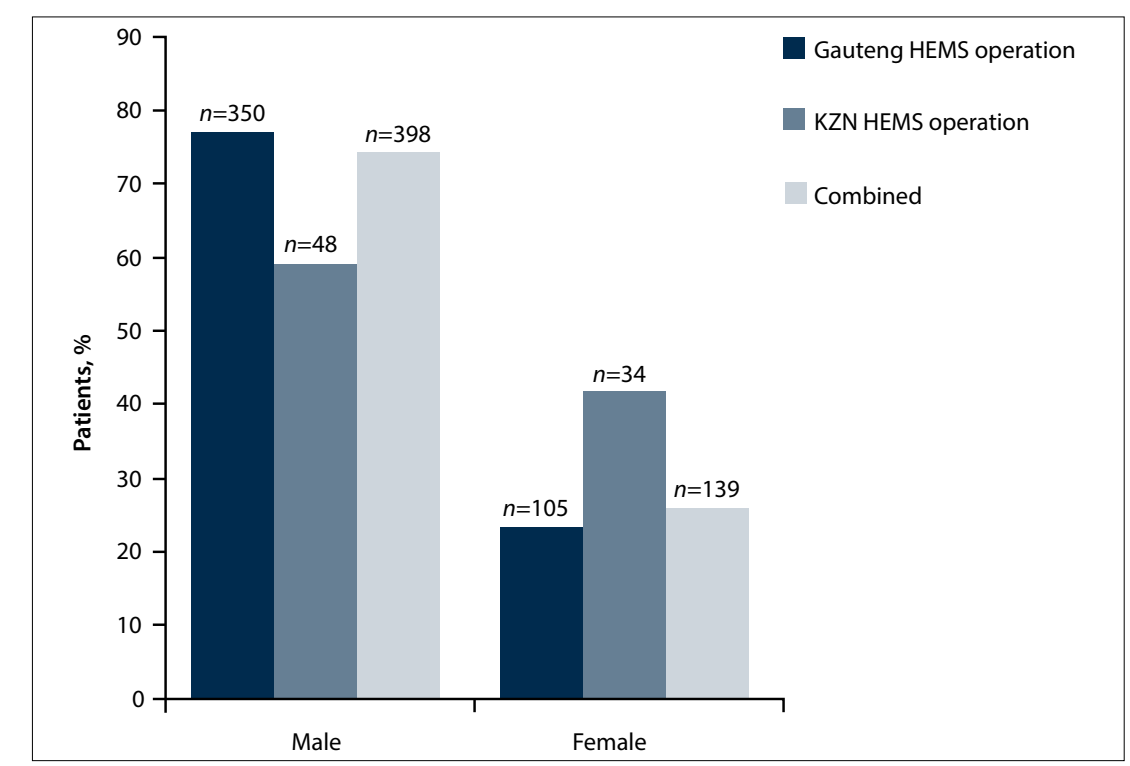

Fig. 1. Gender of patients transported by the Gauteng and KZN HEMS operations.

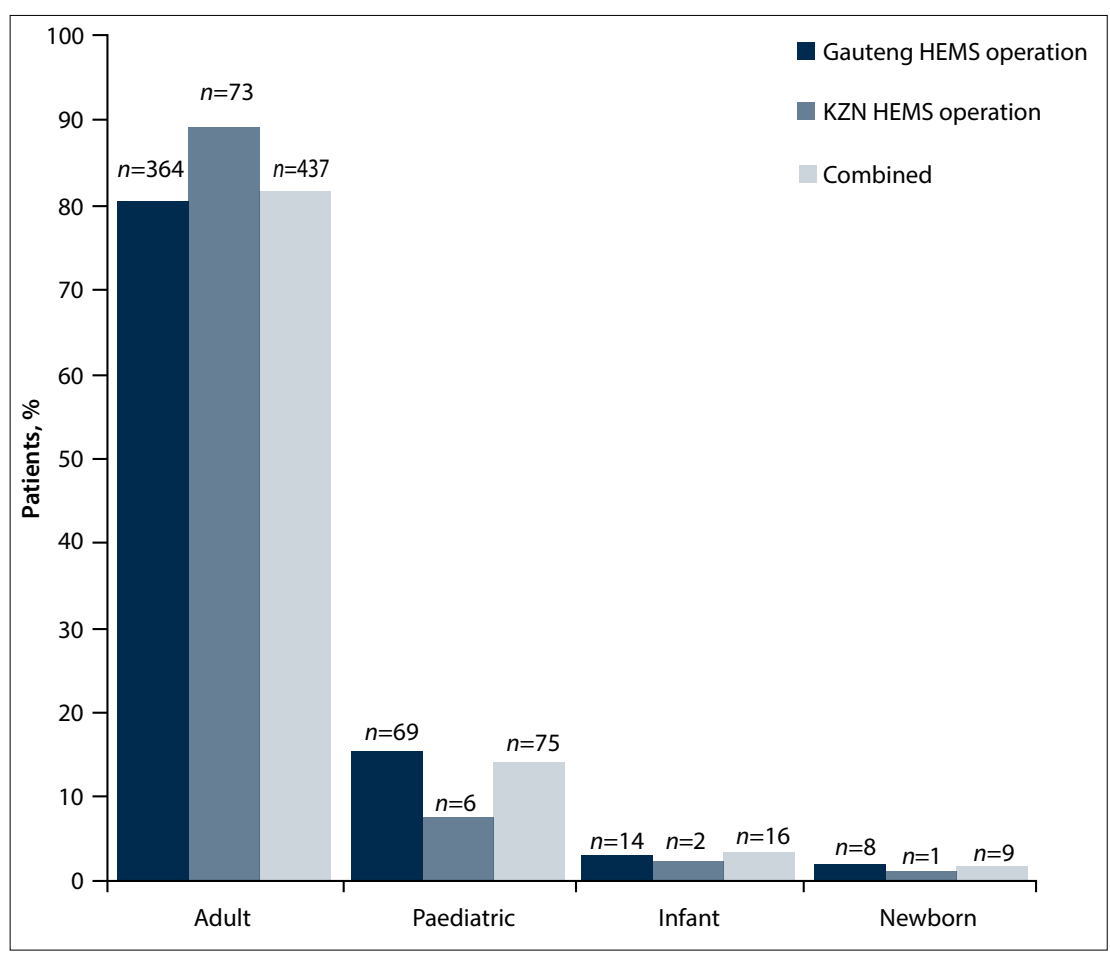

Fig. 2. Ages of patients transported by the Gauteng and KZN HEMS operations.

cipality. These flights were from local medical centres in Bizana and Matatiele, and both were interfacility transfers.

Of the 455 patients transported by the Gauteng HEMS operation, 350 (76.9\%) were males and $105(23.1 \%)$ females, and of the 82 cases transported by the KZN HEMS operation, $48(58.5 \%)$ were males and 34 (41.5\%) females (Fisher's exact test $p=0.001$ ). The ratio of females to males in Gauteng was 1:3, while for KZN it was 1:1.5 (Fig. 1).

Adult patients were transported most frequently by both HEMS operations, the percentages of adult patients flown (Gauteng

Fig. 2. Ages of patients transported by the Gauteng and KZN HEMS operations. 
$n=364,80.0 \%$; KZN $n=73,89.0 \%)$ being significantly higher than the percentages of paediatric patients (Gauteng $n=69,15.2 \%$; KZN $n=6,7.3 \%$ ), infants (Gauteng $n=14$, $3.1 \%$; KZN $n=2,2.4 \%$ ) and neonatal patients (Gauteng $n=8,1.8 \%$; KZN $n=1,1.2 \%$ ) (Fig. 2). The difference in the age groups transported by both the HEMS operations was statistically significant $(p<0.001$, Fisher's exact test).

The main type of incident resulting in patients needing HEMS transport was motor vehicle collisions, with 168 cases for Gauteng (36.9\%) and 25 for KZN (30.5\%) (193/537 (35.9\%) combined). Pedestrianmotor vehicle collisions were also common, with 67 for Gauteng (14.7\%) and 2 for KZN (2.4\%) ( $n=69$ (12.9\%) combined). Of nontrauma-related incident types, cardiac cases were most frequent (Gauteng $n=21$ (4.6\%); KZN $n=16$ (19.5\%); combined $n=37$ (6.9\%)).

The mean flying time to the scene (Gauteng 0:21:00.66 (i.e. 21 minutes and 0.66 seconds); KZN 0:42:10.24) and the mean flying time from the scene to hospital (Gauteng 0:14:37.85; KZN 0:33:30.37) were longer in the KZN HEMS operation missions than in the Gauteng operation (Table 1). The mean on-scene time was very similar for both operations (Gauteng 0:30:46.68; KZN 0:32:20.00). No statistical significance was identified when comparing the mean on-scene times for primary and interfacility transfers (primary transfers 0:30:37.42; interfacility transfers 0:31:46.99) (Table 2).

At the 24-hour follow-up (Fig. 3), 339 patients who had been transported by both services (63.1\%) were alive and stable, 66 $(12.3 \%)$ were dead and $10(1.9 \%)$ had been discharged $(p=0.049)$. At the 72 -hour followup (Fig. 4), 404 patients (75.3\%) were alive and stable, $26(4.8 \%)$ were dead and 37 (6.9\%) had been discharged.

\section{Discussion}

The Netcare 911 HEMS operation in Gauteng was a 24-hour operation, while the KZN operation was a daylight-only service. The cases managed required authorisation through one of four different methods: (i) medical aid; (ii) provincial; (iii) the Road Accident Fund; and (iv) Workmen's Compensation. The provincial authorisation process is tendered for in each provincial area, and only the Gauteng operation was able to fly patients through the provincial authorisation process. Although a number of international studies have been conducted describing types of patients flown, the time frames associated with HEMS transfers, the aeromedical crew and patient outcome, only two local studies have been performed. ${ }^{[7,8]}$

\begin{tabular}{lllll} 
Table 1. Mean time frames & & & & \\
\hline & Mean & SD & Median & IQR \\
\hline Gauteng HEMS & & & & \\
$\quad$ Flying time to scene incident & $0: 21: 00.66$ & $0: 18: 35.52$ & & \\
On-scene time & $0: 30: 46.68$ & $0: 26: 57.95$ & & \\
Flying time to hospital & $0: 14: 37.85$ & $0: 53: 19.37$ & $0: 12: 00.00$ & $0: 10: 00.00$ \\
Total mission time & $1: 55: 49.05$ & $0: 59: 44.01$ & & \\
KZN HEMS & & & & \\
Flying time to scene incident & $0: 42: 10.24$ & $0: 29: 46.46$ & & \\
On-scene time & $0: 32: 20.00$ & $0: 21: 47.67$ & & \\
Flying time to hospital & $0: 33: 30.37$ & $0: 27: 12.84$ & & \\
Total mission time & $2: 34: 40.98$ & $1: 10: 19.76$ & & \\
Combined & & & & \\
Flying time to scene incident & $0: 24: 14.53$ & $0: 22: 01.08$ & & \\
On-scene time & $0: 31: 00.78$ & $0: 26: 14.25$ & & \\
Flying time to hospital & $0: 17: 28.99$ & $0: 50: 41.34$ & $0: 13: 00.00$ & $0: 12: 00.00$ \\
Total mission time & $2: 01: 45.14$ & $1: 02: 58.33$ & & \\
SD = standard deviation; IQR = interquartile range. & & & & \\
& & & &
\end{tabular}

Table 2. Mean on-scene time frames for different transfer types

\begin{tabular}{llll} 
& & \multicolumn{2}{c}{ On-scene time } \\
\cline { 3 - 4 } Type of transfer & $n$ & Mean & SD \\
\hline Primary transfers & 357 & $0: 30: 37.42$ & $0: 26: 29.05$ \\
Interfacility transfers & 180 & $0: 31: 46.99$ & $0: 25: 47.92$ \\
SD = standard deviation. & & &
\end{tabular}

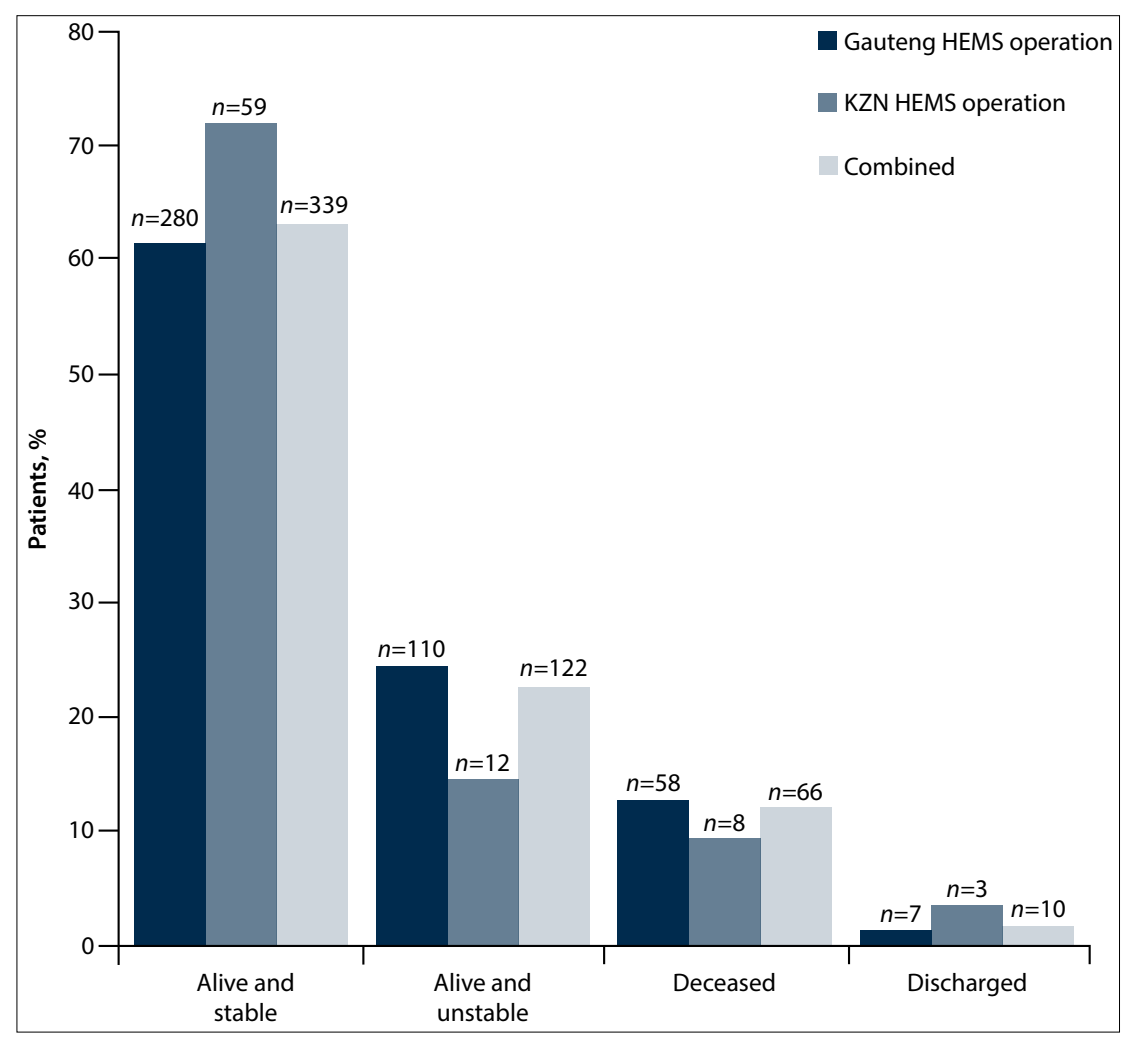

Fig. 3. Patient outcomes after 24 hours. 


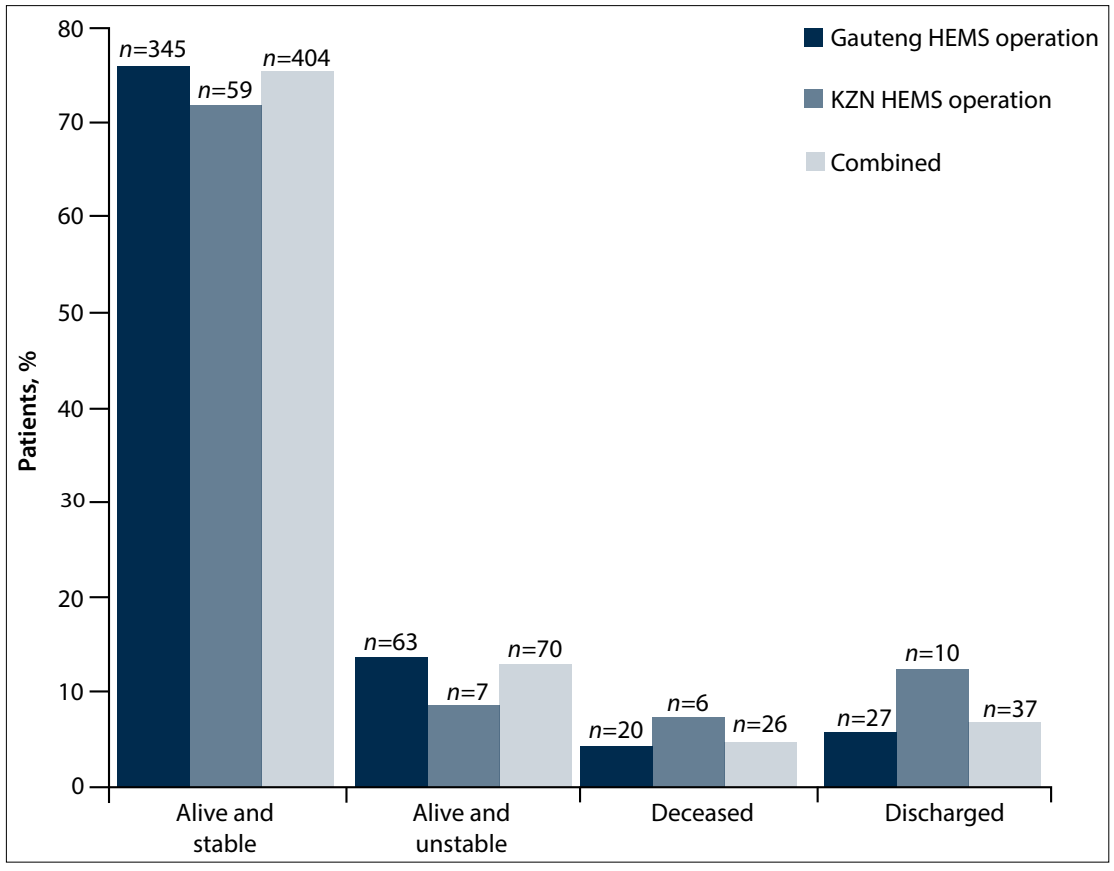

Fig. 4. Patient outcomes after 72 hours.

Our results demonstrated that certain districts in Gauteng and KZN were considerably busier than other districts. Interestingly, the busier districts were more centrally located in the urban areas for both the operations. Although HEMS operations are very expensive to implement and operate, there are certain situations in which helicopters are seen as an acceptable transport resource. ${ }^{[9]}$ This is specifically true for isolated rural areas, and for areas prone to traffic congestion. ${ }^{[10]}$ The Netcare 911 HEMS operations appear to have transported most of their patients from urban areas that are in close proximity to major hospital facilities. While this could possibly reflect traffic congestion, it could not be confirmed, as the time of day of the flights was not routinely recorded for this study. Certain logistical and geographical situations, such as severe traffic congestion, may support HEMS transportation in an urban setting, but it is unwarranted in most cases. ${ }^{[11]}$ Furthermore, a number of studies have determined that transporting a patient by helicopter is not always faster than ground-based transport. A HEMS operation is usually only faster over distances $>45 \mathrm{~km}$, in poor road conditions and when traffic conditions are congested. ${ }^{[12]}$

The majority of the patients transported were adult males. This appears to be in line with international trends, although many studies have only included patients aged $>15$ years. ${ }^{[13,14]}$ Various other studies have had similar findings. In a study conducted in KZN in 1997 on another aeromedical service, of the 398 patients who were trans- ported during the 12 -month study period, males comprised $63 \%$ and females $33 \%$. While the age distribution included patients of all ages, the majority were $<50$ years of age with a mild peak between 21 and 40 years. ${ }^{[15]}$ A more recent study was done on a HEMS operation in Richards Bay, KZN. This included patients of all ages and showed that 797 adult patients (61.9\%) were flown during the 5-year study period, with only 194 paediatric $(15.1 \%)$ and 278 neonatal (21.6\%) patients. ${ }^{[7]}$

The Netcare 911 HEMS operations attended to 357 primary responses (66.5\%) and 180 interfacility transfers (33.5\%) during the study period, with primary responses being the most common type of transfer in both provinces (Gauteng $n=306$ (67.3\%); KZN $n=51(62.2 \%))$. The Gauteng operation had 149 interfacility transfers (32.7\%) and the KZN operation 31 (37.8\%). In the study focusing on the HEMS operation in Richards Bay, the reverse was found, interfacility transfers making up the majority of the cases attended to: of a total of 1418 flights, 1253 (88.4\%) were interfacility transfers and only $165(11.6 \%)$ primary responses. ${ }^{[7]}$ Many international studies have focused on either primary transfers or interfacility transfers, and there have been few studies that included both. Opinions on the potential benefits of HEMS operations for interfacility transfers have differed. One study determined that insufficient evidence is available at this stage to determine the immediate benefits of HEMS over groundbased transport for interfacility transfers, ${ }^{[16]}$ while another determined that the use of HEMS to transport patients for interfacility transfers appeared to provide a time benefit as it reduces transport time. ${ }^{[11]}$ These studies were from high-income countries where the staffing of ground v. air components was identical, which is different to the HEMS staffing in SA.

The most common type of incident to which a helicopter was dispatched was motor vehicle collisions $(n=193,36.0 \%)$. This finding is in line with a number of international studies. ${ }^{[5,17,18]}$ Patients involved in motor vehicle collisions may present with time-sensitive pathologies such as traumatic haemorrhage, polytrauma and traumatic brain injury. Cardiac cases $(n=37,6.9 \%)$ were the most common non-traumatic incident for both the Netcare 911 HEMS operations. Since speed is seen as one of the major advantages of HEMS operations, it is essential that the incident types attended to would potentially benefit from the faster services. Some of the time-sensitive pathologies identified in previous studies were traumatic haemorrhage, ST-elevation myocardial infarction, polytrauma, traumatic brain injury, burns, stroke and paediatric emergencies. ${ }^{[2,19]}$ Polytrauma patients and patients with neurological injuries also appear to derive considerable benefit from doctor-based prehospital care. ${ }^{[14]}$

There can be no doubt that a helicopter is an effective option for patients who have time-sensitive pathologies and are situated in remote areas some distance away from definitive care, as the speed of the operation allows for optimal patient outcome. In such cases, the use of helicopters has many benefits, reducing not only the time to reach the patient, so that critical patient care can be initiated more speedily, but also the time to transport the patient to the most appropriate hospital for further care while administering a high level of care in transit. A helicopter must shorten the time to delivery of care (whether on the scene by skilled aeromedical crew or in hospital) in order to provide any form of benefit to the patient. ${ }^{[2]}$ When comparing the mean on-scene times of both the Netcare 911 HEMS operations with other similarly staffed operations, the mean on-scene times for the Netcare operations were often shorter. ${ }^{[7,20,21]}$ An interesting finding was the similarity between the interfacility transfer and primary transfer on-scene times. The transfer times from scene to hospital for both the Netcare 911 HEMS operations were similar to another SA study. ${ }^{[7]}$ Comparing HEMS transfer times with ground transfer times was not an objective of this study. 
However, HEMS transfer times that are longer than ground transfer times can be justified as the HEMS operation may elect to bypass some of the district hospitals and community clinics in an attempt to source a regional hospital capable of managing a potential surgical emergency as part of definitive care, while ground operations tend to transport patients to the nearest facility. ${ }^{[22]}$

Even though the evidence indicates that HEMS operations can lead to improved outcomes in trauma patients, it would appear that these operations are over-utilised. Adult patients have an over-triage rate of $60 \%$ and paediatric patients an over-triage rate of $85 \%$ in trauma incidents. A meta-analysis of 22 studies determined that one in four HEMS-transported patients were discharged within 24 hours of arrival at a trauma centre, and up to $70 \%$ had non-lifethreatening injuries. ${ }^{[13,23]}$ Analysis of the results of the Netcare 911 HEMS operations shows that there may be a potential for over-triage, as at the 24-hour follow-up point, 339 patients (63.1\%) were alive and stable and $10(1.9 \%)$ had already been discharged. These findings were statistically significant $(p=0.049$ ). At the 72 -hour follow-up, 404 $(75.3 \%)$ were alive and stable and 37 (6.9\%) had been discharged.

A number of studies also reflect the fact that patients with an Injury Severity Score (ISS) of $>15$ require a higher level of specialised care, and this is supported by the finding that HEMS transportation results in a reduction in mortality in these patients. ${ }^{[5,24]}$ In Cudnik et al. $\mathbf{s}^{[13]}$ study, up to $72 \%$ of patients had minor injuries with an ISS of $\leq 15$, suggesting that HEMS operations were being over-utilised. ${ }^{[13]}$ Analysis of our patient outcome statistics indicates that this may also be true for the patients transported by the Netcare 911 HEMS operations.

Although there are some perceived benefits of HEMS operations, the annual costs are very high, ranging in one study from USD115 777 to USD5 571578 per annum. ${ }^{[9]}$ In the SA context, the cost of operating a twin-engine aeromedical helicopter is approximately ZAR30 000 per flying hour. Owing to these significant cost implications, it is crucial that patients are airlifted from locations that would result in some definite benefit to the patient.

\section{Study limitations}

The main limitation of this study was that it included only patients transported by the Netcare 911 HEMS operations in Gauteng and KZN. The other private and provincial HEMS operations across SA were not included. A further limitation was that the cost implications of utilising a HEMS operation instead of a ground operation to transport patients were not a focus area of this study.

\section{Conclusions}

A HEMS operation provides on-board medical personnel with the knowledge, skills and equipment to perform complicated medical procedures and assist in the transfer of ill and/or injured patients to the most appropriate facility. Since HEMS is a very costly resource, it is essential that it be utilised in situations that would offer the most benefit to the patient. While a number of findings were in line with several international and local studies, certain results were concerning, such as potential over-triage and over-use of the HEMS service in the urban environment. Future studies should focus on which specific patients may benefit from HEMS transportation, and the impact of placing the HEMS operation in a rural region.

Acknowledgement. We thank Prof. J K Adam of the Durban University of Technology for her wise input and advice on the developmental phases of this research project and assistance in collating the first author's MTech Emergency Medical Care thesis document (on part of which this article is based) for examination.

\section{References}

1. Farlex. Air ambulance definition 2013. http://www.thefreedictionary.com (accessed 15 September 2011).

2. Floccare DJ, Stuhlmiller DFE, Braithwaite SA, et al. Appropriate and safe utilization of helicopter emergency medical services: A joint position statement with resource document. Prehosp Emerg Care 2013;17(4):521-525. [http://dx.doi.org/10.3109/10903127.2013.804139]

3. Martin T. Aeromedical Transportation: A Clinical Guide. 2nd ed. UK: Ashgate, 2006.

4. Bledsoe BE. EMS myth \# 6: Air medical helicopters save lives and are cost effective. 2003. http://www. emsworld.com (accessed 15 September 2011).

5. Galvagno SM, Haut ER, Nabeel Zafar S, et al. Association between helicopter vs ground emergency medical services and survival for adults with major trauma. JAMA 2012;307(15):1602-1610. [http:// dx.doi.org/10.1001/jama.2012.467]

6. Netcare 911. Netcare 911. 2013. http://netcare911.co.za (accessed 15 September 2013).

7. D'Andrea PA, van Hoving DJ, Smith WP. A 5-year analysis of the helicopter air mercy service in Richards Bay, South Africa. S Afr Med J 2014;104(2):124-126. [http://dx.doi.org/10.7196/SAMJ.7310] 8. Van Hoving DJ, Smith WP, Wallis LA. Comparison of mean on-scene times: Road versus air transportation of critically ill patients in the Western Cape of South Africa. Emerg Med I air transportation of critically ill patients in the Western Cap

9. Taylor CB, Stevenson M, Jan S, Middleton PM, Fitzharris M, Myburgh JA. A systematic review of the 9. Taylor CB, Stevenson M, Jan S, Middleton PM, Fitzharris M, Myburgh JA. A systematic review of the
costs and benefits of helicopter emergency medical services. Injury 2010;41(1):10-20. [http://dx.doi. org/10.1016/j.injury.2009.09.030]

10. Stratton SJ. Should helicopters dispatched for EMS trauma response be grounded? Ann Emerg Med 2013;62(4):365-366. [http://dx.doi.org/10.1016/j.annemergmed.2013.04.003]

11. Brown JB, Gestring ML. Does helicopter transport impact outcome following trauma? Trauma 2013;15(4):279-388. [http://dx.doi.org/10.1177/1460408613497153

12. Melton JT, Jain S, Kendrick B, Deo SD. Helicopter emergency ambulance service (HEAS) transfer: An analysis of trauma patient case-mix, injury severity and outcome. Ann R Coll Surg Engl 2007;89(5):513-516. [http://dx.doi.org/10.1308/003588407X202074]

13. Cudnik MT, Werman HA, White LJ, Opalek JM. Prehospital factors associated with mortality in injured air medical patients. Prehosp Emerg Care 2012;16(1):121-127. [http://dx.doi.org/10.3109/10 903127.2011.615011]

14. Giannakopoulos GF, Kolodzinskyi MN, Christiaans HMT, et al. Helicopter emergency medical services save lives: Outcome in a cohort of 1073 polytrauma patients. Eur J Emerg Med 2013;20(2):7985. [http://dx.doi.org/10.1097/MEJ.0b013e328352ac9b]

15. Johnson B, Dimopoulos GE. An analysis of aeromedical transportation of patients in KwaZulu-Natal. Trauma and Emergency Medicine 1998;August/September:6-8.

16. Schwartz RJ, Jacobs LM, Yaezel D. Impact of pre-trauma center care on length of stay and hospital charges. J Trauma 989;29(12):1611-1615. [http://dx.doi.org/10.1097/00005373-198912000-00002

17. Hassani SA, Moharari RS, Sarvar M, Nejati A, Khashayar P. Helicopter emergency medical service in Tehran, Iran: A descriptive study. Air Med J 2012;31(6):294-297. [http://dx.doi.org/10.1016/j. amj.2012.05.001]

18. McQueen C, Crombie N, Perkins GD, Wheaton S. Impact of introducing a major trauma network on a regional helicopter emergency medicine service in the UK. Emerg Med J 2013;30(7):1-7. [http://dx.doi. org/10.1136/emermed-2013-202756

19. Mommsen P, Bradt N, Zeckey C, et al. Comparison of helicopter and ground emergency medical service: A retrospective analysis of a German rescue helicopter base. Technol Health Care 2012:20(1):49-56.

20. Ringburg AN, Spanjersberg WR, Frankema SPG, Steyerberg EW, Patka P, Schipper IB. Helicopter emergency medical services (HEMS): Impact on scene times. Journal of Trauma, Injury, Infection and emergency medical services (HEMS): Impact on scene times. Journal of Trauma, Injury, Infection and
Critical Care 2007;63(2):258-262. [http://dx.doi.org/10.1097/01.ta.0000240449.23201.57]

21. Butler DP, Anwar I, Willett K. Is it the H or the EMS in HEMS that has an impact on trauma patient mortality? A systematic review of the evidence. Emerg Med J 2010;27(9):692-701. [http://dx.doi. org/10.1136/emj.2009.087486]

22. Hardcastle T. The 11 P's of an Afrocentric trauma system for South Africa - time for action! S Afr Med J 2011;101(3):160-161.

23. Bledsoe BE, Wesley AK, Eckstein M, Dunn TM, O'Keefe MF. Helicopter scene transport of trauma patients with nonlife-threatening injuries: A meta-analysis. J Trauma 2006;60(6):1257-1265. [http:// dx.doi.org/10.1097/01.ta.0000196489.19928.c0]

24. Nicholl JP, Brazier JE, Snooks HA. Effects of London helicopter emergency medical service on survival after trauma. BMJ 1995;311(6999):217-222. [http://dx.doi.org/10.1136/bmj.311.6999.217] 